Pak. j. sci. ind. res. Ser. B: biol. sci. 201154 (3) 152-156

\title{
Laboratory Evaluation of Toxic and Repellent Properties of Dracaena arborea Against Sitophilus zeamais and Callosobruchus maculatus
}

\author{
Ime Okon Udo \\ Department of Crop Science, University of Uyo, Uyo, Nigeria
}

(received August 11, 2010; revised September 5, 2011; accepted September 17, 2011)

\begin{abstract}
Laboratory evaluation of ethanolic extract of Dracaena arborea leaves partitioned between equal volumes of chloroform, ethyl acetate, $n$-hexane and $n$-butanol to obtain various fractions was carried out to assess contact toxicity on filter paper and by topical application, toxicity of extracts applied on grains and repellent action against Sitophilus zeamais (Mots.) and Callosobruchus maculatus Fabricius on stored grains. Insects were exposed to both treated and untreated surfaces and mortality was scored at different times after treatment. Results obtained from the study showed the extract fractions causing significant mortality of both insects exposed to treatments. A contact toxicity of over $80 \%$ was recorded against S. zeamais from ethyl acetate fraction. Similarly, $100 \%$ mortality was recorded against C. maculatus from ethyl acetate fraction after $96 \mathrm{~h}$ of treatment. Results obtained from grain treatment produced a significant mortality of over $60 \%$ against $C$. maculatus from $n$-hexane fraction while the aqueous fraction significantly killed $S$. zeamais by over $15 \%$ compared with the control treatment. A strong repellent action was evoked against $S$. zeamais while moderate action was recorded against $C$. maculatus. An overall repellency of $40 \%$ and $24 \%$ was recorded from various extract fractions against $S$. zeamais and C. maculatus, respectively. The results obtained suggest a promising alternative to synthetic insecticides and the incorporation of D. arborea into storage pest management system is advised.
\end{abstract}

Keywords: toxicity, Sitophilus zeamis, Dracaena arborea, stored grains, extract fractions maculatus, Callosobruchus, repellency

\section{Introduction}

Grains in storage are subject to insect pest infestation if left without protectants and the consequence is serious threat to food security. There are records of enormous losses of up to $20-30 \%$ of stored products arising from insect pest attacks (Obeng-Ofori, 1995). Insect pests associated with stored products are beetles and moths with the common ones being Sitophilus zeamais and Callosobruchus maculatus attacking stored maize and cowpea, respectively. Over the years farmers relied upon the use of synthetic chemicals for the control of storage pests. The attendant consequences of the use of synthetic chemicals have been widely reported (Udo et al., 2004; Obeng-Ofori, et al., 1997; White, 1995; Shaaya et al., 1991; Zettler and Cuperus, 1990). Alternative control measures are still being sougth out and one of them is the use of plant materials and plant products. Botanical treatments have been found to be safer to the environment, broad spectrum in action with little or no hazards to man and other animals. One such plant is Dracaena arborea which is a tropical plant growing up to $15 \mathrm{~m}$ high and $2.5 \mathrm{~m}$ girth with

E-mail:imeudo@yahoo.com long, broad and blade-like leaves, and commonly utilized as boundary plants for demarcation of plots of land in the Southeastern parts of Nigeria. Okunji et al. (1996) has reported that anti-fungal and anti-parasitic compounds are present in D. arborea.

In this study, ethanolic extract fractions of $D$. arborea were screened for insecticidal activities against $S$. zeamais and $C$. maculatus. Extract fractions have the advantage of economic use of the plant material especially where the plant is not readily available and could also be used for such tests like repellency and tropical bioasssay.

\section{Materials and Methods}

Insects. S. zeamais and C. maculatus were collected from infested stock of grains at Etaha Itam market, Uyo, Nigeria and reared on sterilized maize and cowpea grains, respectively. After two weeks of oviposition, the parent adults were removed by sieving while emerging progeny were recultured and used for various bioassays.

Preparation of extract fractions. Leaves of $D$. arborea with voucher number UUH (84a), Faculty of Pharmacy, University of Uyo, were collected from the wild in Uyo, 
Nigeria and air dried in the laboratory for five days. Dried leaves were ground and $1 \mathrm{~kg}$ soaked in $90 \%$ ethanol in glass jars and left to stand in the dark for $72 \mathrm{~h}$ to prevent possible volatilization of active principles. Filtration was carried out and ethanol was evaporated using rotary evaporator. The residue obtained was dissolved in $60 \mathrm{~mL}$ of distilled water and subjected to partitioning using equal volumes of $n$-hexane, chloroform, ethyl acetate and $n$ butanol to obtain different extract fractions used for the various bioassays.

Contact toxicity on filter paper. Whatman No. 1 filter paper (10.9 cm diameter) placed in glass petri dishes was impregnated with $200 \mu \mathrm{L} / \mathrm{mL}$ of each extract fraction and 10 adults each of $S$. zeamais and $C$. maculatus were introduced into each dish, respectively. Control treatments had the filter paper impregnated with distilled water and mortality was recorded after $24 \mathrm{~h}$ and up to $96 \mathrm{~h}$. Insects were assumed dead on failure to respond to three probes with a blunt dissecting probe after a 5-min recovery time.

Contact toxicity by topical application. Forty adult insects, each of $S$. zeamais and $C$. maculatus were chilled in the deep freezer for three minutes to reduce their activity (mobility) and transferred into petri dishes. One micro litre of each extract fraction was applied using a micro pipette to the dorsal surface of the thorax of each insect taken individually. Distilled water was applied to control insects and each treatment was replicated four times. Mortality was recorded after one hour for $48 \mathrm{~h}$.
Toxicity of extracts applied on grains. Toxicity of the extract fractions applied on maize and cowpea grains, respectively, against $S$. zeamais and $C$. maculatus was tested by applying $200 \mathrm{mg} / \mathrm{kg}$ to $50 \mathrm{~g}$ of grains in a 200 $\mathrm{mL}$ plastic cup. Ten pairs of each insect species were introduced into treated and control grains. Mortality was recorded after $24 \mathrm{~h}$ and up to $96 \mathrm{~h}$ after treatment with insects presumed dead on failure to respond to three probes with a blunt dissecting probe.

Repellency test. Repellent effect of the extract fractions was tested using the method described by Obeng-Ofori et al. (1997). Whatman No.1 filter paper were cut into halves with one half being treated with the extract fractions while the other half was treated with distilled water to serve as the control. After being air dried for one hour, the full discs were re-made by attaching treated and control halves with paper tapes. Each filter paper was placed in a petri dish and ten weevils introduced into the center of the paper. Number of weevils present on control (Nc) and treated (Nt) strips were recorded after $30 \mathrm{~min}$ and up to $48 \mathrm{~h}$. Percent, repellency was computed as:

$$
\mathrm{PR}=\frac{\mathrm{Nc}-\mathrm{Nt}}{\mathrm{Nc}+\mathrm{Nt}} \times 100 \%
$$

Where:

$\mathrm{PR}=$ percent repellency

$\mathrm{Nc}=$ number of insects present on control strip

$\mathrm{Nt}=$ number of insects present on treated strip.

Table 1. Contact toxicity of extract fractions of $D$. arborea applied on filter paper against $S$. zeamais and C. maculatus

\begin{tabular}{|c|c|c|c|c|c|c|}
\hline \multirow{2}{*}{$\begin{array}{l}\text { Extract fractions } \\
(200 \mu \mathrm{L} / \mathrm{mL})\end{array}$} & \multicolumn{4}{|c|}{ Percent mortality after treatment } & \multirow[t]{2}{*}{ Control } & \multirow[t]{2}{*}{ LSD } \\
\hline & $24 \mathrm{~h}$ & $48 \mathrm{~h}$ & $72 \mathrm{~h}$ & $96 \mathrm{~h}$ & & \\
\hline \multicolumn{7}{|l|}{ S. zeamais } \\
\hline Ethyl acetate & $7 \pm 0.50$ & $17 \pm 0.95$ & $28 \pm 1.25$ & $82 \pm 2.44$ & $0 \pm 0.00$ & 10.40 \\
\hline Chloroform & $0 \pm 0.00$ & $17 \pm 0.95$ & $33 \pm 1.73$ & $47 \pm 1.25$ & $0 \pm 0.00$ & 31.60 \\
\hline$n$-hexane & $0 \pm 0.00$ & $0 \pm 0.00$ & $8 \pm 0.50$ & $17 \pm 0.50$ & $0 \pm 0.00$ & 9.60 \\
\hline$n$-butanol & $0 \pm 0.00$ & $7 \pm 0.50$ & $8 \pm 0.50$ & $12 \pm 0.81$ & $0 \pm 0.00$ & NS \\
\hline Aqueous & $7 \pm 0.50$ & $7 \pm 0.50$ & $23 \pm 0.81$ & $62 \pm 0.81$ & $0 \pm 0.00$ & 18.00 \\
\hline \multicolumn{7}{|l|}{ C. maculatus } \\
\hline Ethyl acetate & $0 \pm 0.00$ & $0 \pm 0.00$ & $13 \pm 0.81$ & $13 \pm 0.81$ & $0 \pm 0.00$ & NS \\
\hline Chloroform & $0 \pm 0.00$ & $0 \pm 0.00$ & $0 \pm 0.00$ & $0 \pm 0.00$ & $0 \pm 0.00$ & NS \\
\hline$n$-hexane & $7 \pm 0.50$ & $7 \pm 0.50$ & $23 \pm 0.81$ & $23 \pm 0.81$ & $0 \pm 0.00$ & NS \\
\hline$n$-butanol & $0 \pm 0.00$ & $7 \pm 0.50$ & $18 \pm 0.95$ & $18 \pm 0.95$ & $0 \pm 0.00$ & NS \\
\hline Aqueous & $7 \pm 0.50$ & $7 \pm 0.50$ & $13 \pm 0.81$ & $13 \pm 0.81$ & $0 \pm 0.00$ & NS \\
\hline
\end{tabular}

Means $=(\mathrm{SEM})$ of four replicates of 20 insects each; LSD test $=(\mathrm{P}<0.05) ; \mathrm{NS}=$ Non significant. 
Table 2. Toxicity of extract fractions of $D$. arborea applied topically against $S$. zeamais and $C$. maculatus

\begin{tabular}{|c|c|c|c|c|c|c|}
\hline \multirow{2}{*}{$\begin{array}{l}\text { Extract fractions } \\
20 \mu \mathrm{g} / \mathrm{mL}\end{array}$} & \multicolumn{4}{|c|}{ Percent mortality after treatment } & \multirow[t]{2}{*}{ Control } & \multirow[t]{2}{*}{ LSD } \\
\hline & $24 \mathrm{~h}$ & $48 \mathrm{~h}$ & $72 \mathrm{~h}$ & $96 \mathrm{~h}$ & & \\
\hline \multicolumn{7}{|l|}{ S. zeamais } \\
\hline$n$-hexane & $0 \pm 0.00$ & $0 \pm 0.00$ & $5 \pm 0.50$ & $10 \pm 0.57$ & $0 \pm 0.00$ & NS \\
\hline$n$-butanol & $70 \pm 1.73$ & $75 \pm 1.89$ & $75 \pm 1.89$ & $85 \pm 1.50$ & $0 \pm 0.00$ & 47.40 \\
\hline Chloroform & $0 \pm 0.00$ & $0 \pm 0.00$ & $10 \pm 0.57$ & $15 \pm 0.50$ & $0 \pm 0.00$ & 10.40 \\
\hline Ethyl acetate & $15 \pm 0.95$ & $35 \pm 0.95$ & $40 \pm 0.82$ & $65 \pm 0.95$ & $0 \pm 0.00$ & 24.80 \\
\hline Aqueous & $95 \pm 0.50$ & $100 \pm 0.00$ & $100 \pm 0.00$ & $100 \pm 0.00$ & $0 \pm 0.00$ & 7.40 \\
\hline \multicolumn{7}{|l|}{ C. maculatus } \\
\hline$n$-hexane & $0 \pm 0.00$ & $10 \pm 1.00$ & $15 \pm 1.38$ & $25 \pm 1.89$ & $0 \pm 0.00$ & NS \\
\hline$n$-butanol & $95 \pm 0.50$ & $95 \pm 0.50$ & $95 \pm 0.50$ & $95 \pm 0.50$ & $0 \pm 0.00$ & 13.40 \\
\hline Chloroform & $0 \pm 0.00$ & $0 \pm 0.00$ & $0 \pm 0.00$ & $10 \pm 0.57$ & $0 \pm 0.00$ & NS \\
\hline Ethyl acetate & $95 \pm 0.50$ & $100 \pm 0.00$ & $100 \pm 0.00$ & $100 \pm 0.00$ & $0 \pm 0.00$ & 6.80 \\
\hline Aqueous & $95 \pm 0.50$ & $100 \pm 0.00$ & $100 \pm 0.00$ & $100 \pm 0.00$ & $0 \pm 0.00$ & 7.40 \\
\hline
\end{tabular}

Means $=(\mathrm{SEM})$ of four replicates of 10 insects each; LSD test $=(\mathrm{P}<0.05)$; NS $=$ Non significant.

Table 3. Percent mortality of $S$. zeamais and $C$. maculatus exposed to grains treated with extract fractions of D. arborea

\begin{tabular}{|c|c|c|c|c|c|c|}
\hline \multirow{2}{*}{$\begin{array}{l}\text { Extract fractions } \\
(200 \mathrm{mg} / \mathrm{kg})\end{array}$} & \multicolumn{4}{|c|}{ Percent mortality after treatment } & \multirow[t]{2}{*}{ Control } & \multirow[t]{2}{*}{ LSD } \\
\hline & $24 \mathrm{~h}$ & $48 \mathrm{~h}$ & $72 \mathrm{~h}$ & $96 \mathrm{~h}$ & & \\
\hline \multicolumn{7}{|l|}{ S. zeamais } \\
\hline$n$-hexane & $0 \pm 0.00$ & $5 \pm 0.81$ & $5 \pm 0.50$ & $5 \pm 0.50$ & $0 \pm 0.00$ & 3.60 \\
\hline Chloroform & $0 \pm 0.00$ & $5 \pm 0.57$ & $5 \pm 0.50$ & $5 \pm 0.50$ & $0 \pm 0.00$ & 3.00 \\
\hline Ethyl acetate & $0 \pm 0.00$ & $5 \pm 0.57$ & $5 \pm 0.81$ & $10 \pm 1.00$ & $0 \pm 0.00$ & 4.75 \\
\hline$n$-butanol & $0 \pm 0.00$ & $5 \pm 1.00$ & $5 \pm 1.00$ & $5 \pm 1.00$ & $0 \pm 0.00$ & NS \\
\hline Aqueous & $5 \pm 1.15$ & $5 \pm 1.15$ & $15 \pm 1.29$ & $15 \pm 1.47$ & $0 \pm 0.00$ & 8.45 \\
\hline \multicolumn{7}{|l|}{ C. maculatus } \\
\hline$n$-hexane & $10 \pm 2.16$ & $35 \pm 2.71$ & $40 \pm 2.60$ & $60 \pm 2.98$ & $0 \pm 0.00$ & 12.20 \\
\hline Chloroform & $10 \pm 2.87$ & $30 \pm 3.77$ & $35 \pm 4.69$ & $45 \pm 5.83$ & $0 \pm 0.00$ & 29.85 \\
\hline Ethyl acetate & $5 \pm 1.41$ & $25 \pm 2.44$ & $30 \pm 2.98$ & $40 \pm 3.68$ & $0 \pm 0.00$ & 18.60 \\
\hline$n$-butanol & $10 \pm 2.06$ & $30 \pm 1.25$ & $35 \pm 1.82$ & $50 \pm 1.71$ & $0 \pm 0.00$ & 11.70 \\
\hline Aqueous & $15 \pm 1.91$ & $20 \pm 2.50$ & $20 \pm 2.50$ & $25 \pm 2.06$ & $0 \pm 0.00$ & 15.20 \\
\hline
\end{tabular}

Means $=($ SEM $)$ of four replicates of 20 insects each; LSD test $=(P<0.05)$; NS $=$ Non significant.

\section{Results and Discussion}

Contact toxicity on filter paper. Results of the toxic effect of extract fractions of $D$. arborea applied on filter paper against $S$. zeamais and C. maculatus is shown in Table 1. There was a contact mortality of $80 \%$ from the ethyl acetate fraction while $n$-hexane and chloroform fractions recorded a mortality of $45 \%$ and $15 \%$, respectively after $96 \mathrm{~h}$ of treatment against S. zeamais. The aqueous fraction also significantly induced a mortality of $60 \%$ in S. zeamais after $96 \mathrm{~h}$ of insect exposure to treated filter papers.
Contact toxicity by topical application. Significant insect mortality was recorded from topical application of the different extract fractions against the two insect species (Table 2). Ethyl acetate and the aqueous fractions were observed to induce $100 \%$ mortality of the insects after $96 \mathrm{~h}$ treatment.

Toxicity of the extract fractions applied on grains. Different levels of toxicity of the extract fractions were observed against $S$. zeamais and C. maculatus after $96 \mathrm{~h}$ of exposure to treated grains (Table 3 ). The $n$-hexane fraction recorded a mortality of $60 \%$ against $C$. maculatus while the aqueous fraction produced $15 \%$ mortality in S. zeamais. 
Table 4. Percent repellency (PR) values for extract fractions of $D$. arborea tested against $S$. zeamais and $C$. maculatus

\begin{tabular}{lll}
\hline \hline Extract fraction & \multicolumn{2}{l}{ Mean percent repellency } \\
\cline { 2 - 3 } & S. zeamais & C. maculatus \\
\hline$n$-hexane & 38 & 42 \\
Chloroform & 44 & 6 \\
Ethyl acetate & 44 & 25 \\
$n$-butanol & 25 & 13 \\
Aqueous & 50 & 33 \\
Overall PR & 40 & 24 \\
LSD & 11.04 & 17.46 \\
\hline \hline
\end{tabular}

Mean $=(\mathrm{SEM})$ of four replicates of 10 insects each; LSD test $=(\mathrm{P}<0.01)$.

Repellency test. Table 4 shows the repellent effect of the various extract fractions against the two insect species with $S$. zeamais being significantly repelled by about $40 \%$ while $C$. maculatus had an overall repellency of $24 \%$. The individual extract fractions showed the aqueous fraction repelling $S$. zeamais and $C$. maculatus by $50 \%$ and $33 \%$, respectively. Ethyl acetate fraction also repelled $S$. zeamais and $C$. maculatus by about $44 \%$ and $25 \%$, respectively.

The significant mortality of $S$. zeamais in filter paper impregnated with the extract fractions indicated the presence of residual toxic principle in D. arborea. Some secondary metabolites identified as mannispirostan A and spiroconazole A have been identified in D. arborea (Okunji et al., 1996). S. zeamais was more susceptible to filter paper treatment of the extract fractions probably because of their close contact with treated surfaces, compared to $C$. maculatus which were observed to be very mobile and hanging on the underside of perforated petri dish covers. This observation has also been reported against these insect pests when tested against methanol extract of Zanthoxylum xanthoxyloides Lam. (Udo et al., 2004, Ofuya and Okuku, 1994).

The extract fractions applied topically against $S$. zeamais and $C$. maculatus induced significant insect mortality of the two insect species and dead beetles were found having their metathoracic wings stretched outside the elytra thus suggesting contact toxicity and not due to ingestion of treated grains (Obeng-Ofori et al., 1997). Topical application therefore, facilitated the direct contact of toxicants or active ingredients in D. arborea with insects' bodies (Adedire and Ajayi, 1996). Udo and Epidi (2009) reported similar results on the efficacy of ethanolic extract fractions of Ricinodendron heudelotii (Baill) Pierre ex Pax against the two insect pests.

C. maculatus was more susceptible to contact action of the extract fractions applied on grains than $S$. zeamais probably because of the absence of hard and highly sclerotized thoracic cuticle as in their Sitophilus counterpart. Similar results were obtained by other researchers (Epidi et al., 2008; Owusu et al., 2007), who reported on the efficacy of the leaf powder of $D$. arborea against the two insect species.

The significant repellent action observed against $S$. zeamais and C. maculatus is noteworthy as this could prevent the insects from settling, feeding and laying eggs into grains protected with extracts of $D$. arborea. The result obtained from this study recommends the incorporation of $D$. arborea in storage pest management systems particularly in Africa. It could become an important supplement or alternative to synthetic insecticides.

\section{Acknowledgement}

The author is grateful to Dr. (Mrs.) Uduak Essiett, a Botanist in the University of Uyo for identifying the plant specimen.

\section{References}

Adedire, C.O., Ajayi, T.S. 1996. Assessment of the insecticidal properties of some plant extracts as grain protectants against the maize weevil, Sitophilus zeamais Motschulsky. Nigerian Journal of Entomology, 13: 93-101.

Epidi, T.T., Nwanin, C.D., Udoh, S. 2008. Efficacy of some plant species for the control of cowpea weevil (Callosobruchus maculatus) and maize weevil (Sitophilus zeamais). International Journal of Agriculture and Biology, 10: 588-90.

Obeng-Ofori, D. 1995. Plant oils as grain protectants against infestations of Cryptolestes pusillus and Rhyzopertha dominica in stored grain. Entomologia Experimentalist et Applicata, 77: 133-139.

Obeng-Ofori, D., Reichmuth, C.H., Bekele, J., Hassanali, A. 1997. Biological activity of 1,8 cineole, a major component of essential oil of Ocimum kenyense (Ayobangira) against stored product beetles. Journal of Applied Entomology, 121: 237-243.

Ofuya, T.I., Okuku, I.E. 1994. Insecticidal effect of some plant extracts on the cowpea aphid Aphis craccivora Koch (Homoptera: Aphididae). Anzeiger fur Schadlingskunde, Pflanzenschutz, Umweltschutz, 67: 127-129. 
Okunji, C.O., Iwu, M.M., Jackson, J.E., Tally, J.D. 1996. Biological activity of saponins from two Dracaena species. Advances in Experimental Medicine and Biology, 404: 415-428.

Owusu, E.O., Osafo, W.K., Nutsukpui, E.R. 2007. Bioactivities of Candlewood, Zanthoxylum xanthoxyloides (Lam.) solvent extracts against two stored-product insect pests. African Journal of Science and Technology, 8: 17-21

Shaaya, E., Ravid, U., Poster, N., Juven, B., Zisman, U., Pissarev, V. 1991. Fumigant toxicity of essential oils against four major stored products insects. Journal of Chemical Ecology, 17: 499-504.

Udo, I.O., Epidi, T.T. 2009. Biological effect of ethanolic extract fractions of Ricinodendron heudelotii (Baill) Pierre ex Pax against Sitophilus zeamais and Callosobruchus maculatus Fabricius on stored grains. African Journal of Agricultural Research, 4: 1080-1085.

Udo, I.O., Obeng-Ofori, D., Owusu, E.O. 2004. Biological effect of methanol extracts of Candlewood Zanthoxylum xanthoxyloides (Lam) against infestation of stored maize and cowpea by three stored products beetles. Global Journal of Pure and Applied Sciences, 10: $227-233$.

White, N.D.G. 1995. Insect, mites and insecticides in stored grain ecosystems. In: Stored Grain Ecosystem, D. S. Jayas, N. D. G. white and W. E. Muir (eds.), pp. 123168, Marcel Dekker, NY., USA.

Zettler, J.L., Cuperus, G.W. 1990. Pesticide resistance in Tribolium castaneum (Coleoptera: Tenebrionidae) and Rhizopertha dominica (Coleoptera: Bostrichidae) in wheat. Journal of Economic Entomology, 83: 1677-1681. 